\title{
Relations Between the Athletic Department and Sports Clubs in Albania. the Research in the Department of Athletics
}

\author{
Madrit Isufi \\ Physical Education Teacher \\ isufimadrit@gmail.com
}

\begin{abstract}
"Athletics teaches lessons valuable to the individual by stretching the human spirit in ways that nothing else can" (Bowen \& Levin, 2003, p. 243).

In Albania there is a great andikap in the field of athletics. University knowledge related to this field remains at the level of undergraduate banks materialize in practice. Athletic Department is not an agreement with the clubs that train athletes or sports clubs for football are that the atletikor preparers often include as an assistant coach. Finally there is an initiative of the Ministry of Education and Sports to establish such cooperation and relations to make this part of plans and curricula, but it still has not been realized in practice, because Albania has an acute shortage of infrastructure.
\end{abstract}

International Athletics Federation signed a memorandum of understanding with the Albanian Federation of Athletics. The aim was to help with programs for children, education of coaches and support initiatives for athletics at competitive levels. Also to support initiatives to better structure sportive. But that relations remained on paper, today manufactures athletic department student and prepare new trainers but without a vision for the space you created them employment, there is a vision for it, no one strategy and what is the most important projects there is cooperation with other countries to support athletic clubs and strengthen the work of professors athletic field with trainers.

This study is important in helping gain an understanding of the relationship between coaches' trust and how he or she perceives the athletic-director's mindfulness within the athletic department. Lumpkin and Favor (2012) stated that "proponents of high school sport programs believe athletics contribute to the overall education of students" (p. 41). Sports play an important role in the Albanian society. Although high school sports are popular, more importantly many believe they are avenues for providing opportunities for justice, fair play, and teamwork.

Sports and athletics express many of the cultural beliefs held by society, including the Protestant work ethic, capitalism, the bureaucratic mentality, and the ideals of fairness, teamwork, and sportsmanship, all of which are associated with collectivism (Beyer \& Hannah, 2000).

\section{Statement of the Problem}

Some of the disadvantages to high school sports are undue stress, time commitment, physical injury, and unsportsmanlike behavior (Duda, Olson, \& Templin, 1991). According to the National Center for Sports Safety (http://www. sportssafety. org), more than 3 million children under the age of 14 incur some type of injury as a result of sports. Unsportsmanlike behavior is modeled in a variety of sporting situations. In both practice and competitive events, children are exposed to other children who may exhibit undesirable behavior (Duda, Olson, \& Templin, 1991)

In fact, studies have indicated that participation in athletics can lead to the experience of negative outcomes. Tatum (2007) suggested that school leaders, in this case high school athletic departments and coaches, must be intentional in their efforts to positively influence the lives of their student-athletes. Without staff members being intentional, student-athletes will not reap the potential benefits of participation (Doty, 2006). The research on high school sports suggest those student-athletes may experience similar harm to that felt by adolescent athletes in that intensive competition at an early age may turn kids away from sports. 
According to Judge and Judge (2009), Traditionally, the job of athletic director was viewed as a nonthreatening reward offered to a coach at the conclusion of a career. As the basic mission of the secondary public school expanded over the past decades, so did the responsibilities of the athletic director. School corporations typically hire individuals, for the position of athletic director, who are already trained in producing results, experienced in program management, who have administration skills that are specific to budgets, personnel, event planning, fundraising and marketing. (p. 37)

The athletic director holds a vital position in the scope of the total school program. The trend today is to have the athletic director as part of the school's administration. The responsibilities of the position have grown so much that a full-time administrator is often needed to manage the athletic department. The athletic director is responsible for the business administration of the department, which means performing managerial functions. The amount of time allotted and the amount of support given varies widely from school system to school system.

"Theoretically and empirically, trust is necessary for school mindfulness and school mindfulness reinforces a culture of trust" (Hoy, Gage, \& Tarter, 2006, p. 252). Organizations can be designed in ways that facilitate or discourage trustworthy actions from those involved. The structure, policies, and culture of an organization can impact the level of trustworthiness within the organization (Wenger, 1998). High school athletic departments are no different. These departments might be structured so that the coaching staff is given high levels of freedom over all decisions made within. The athletic director desires to create an environment in which the coaches can have this freedom and that they can know that they are trusted with the decision-making process.

\section{The purpose of this study was}

to explore two of the organizational social processes (mindfulness and trust) within high school athletic departments. In this research, it is assumed that mindful organizations develop open and trusting relationships between the athletic directors and the coaches within the department. If valid, the results from the study could benefit the department by providing information that might change the relationships, attitudes, and approaches to the high school athletic setting.

\section{Terminology:}

Athletic Director (or Director of Athletics) refers to the person responsible for the entire operation of the athletic program, including planning, organizing, leading, and evaluating coaches and other personnel within the department. He or she is simultaneously a mentor, a businessperson, a motivator, and an enforcer (Branch, 1990).

Coaches are designated as paid or volunteer members of the athletics department staff who are under contract to perform both on and off the field/court duties (e. g. communication, 
planning, and networking), as well as developing knowledge in a number of areas (e. g.

pedagogy, psychology, sociology) (Nash \& Sproule, 2009).

Colleagues refer to those coaches (head and assistant) who work in the same athletic department.

Mindfulness refers to organizations and individuals who exhibit the following five characteristics: preoccupation with failure, a reluctance to simplify, sensitivity to operations, a commitment to resilience, and deference to expertise (Hoy, Gage, \& Tarter, 2006).

\section{Research Questions}

1. What is the right ratio between autonomy of sport and intervention

the law to fix an issue public importance as sport?

2. Does a linear relationship of trust in colleagues, athletic director, and student-athlete predict athletic director mindfulness?

3. Is a coach's trust in colleagues a good predictor of his/her perception of mindfulness of the athletic director?

\section{Organizational Mindfulness Research}

Organizational mindfulness, in social science terms, is a relatively new phenomenon and as such there has been surprisingly little empirical research (Baker, 2007; Knight, 2004). To complicate matters, the extant research has explored mindfulness with diverse methodologies so there has been a lack of consistency regarding the findings. As a result, how the construct of organizational mindfulness is actually manifested remains unclear (Knight, 2004). Highlighting the range of the research on the subject, a description of three conceptual studies, among the earliest explorations into mindfulness will be reviewed.

Fiol and O'Connor (2003) explored the impact of mindfulness on bandwagon behavior in the health care setting. In the study, they proposed a conceptual model that detailed the relationship of mindfulness and bandwagon avoidance. Bandwagon behaviors refer to individuals or organizations adopting an idea or technique due to pressures from other organizations. Without careful consideration, the bandwagon behavior can cause many 
organizations to respond to popular persuasion rather than sound principles and analyses.

\section{Facets of Trust}

Trust is a concept with at least five facets: benevolence, predictability, competence, honesty, and openness (Hoy et al., 2006). Each of these elements is based on common beliefs that individuals or groups act in ways that are in the best interest of the parties involved. A key underlying element is the concept of risk. Trust does involve taking risk and making oneself vulnerable to another with confidence that the latter will act in a way that is not detrimental to the other party (Hoy et al., 2006).

\section{The Relationship Between Organizational Trust and Mindfulness}

The review of the literature indicated that organizational mindfulness has been understudied in high school settings and completely unstudied in high school athletic departments. Likewise, the construct of organizational trust has been understudied in higher education and has yet to be studied in high school athletic departments. The current study added a deeper understanding of trust and mindfulness as it relates to coaches, athletic directors, and student-athletes at the high school level.

Evidence that all five mindfulness principles impacted faculty trust (preoccupation with failure, reluctances to simplify, sensitivity to operations, commitment to resilience, and deference to expertise) was found in the exploration of organizational trust and mindfulness conducted by (Hoy et al., 2006). Using a series of factor analyses, Hoy et al. (2006) found two mindfulness factors: principal mindfulness and faculty mindfulness, both of which measured all five components. These two factors combined to create what they labeled as organizational mindfulness. In the study of 75 middle schools, they found lower levels of within school variance than between school variance, leading them to conclude that mindfulness is a collective property. Using multiple regression analysis, Hoy et al. (2006) found that the three faculty trust variance in faculty mindfulness.

Additionally, they discovered faculty trust in principal was a significant predictor of principal mindfulness and faculty trust in clients had limited influence on mindfulness. Overall, they found organizational mindfulness to be best explained by both trust in colleagues and trust in their principal. 
Whereas organizational trust and mindfulness seem to be important aspects of the school

environment, research needs to explore their relationship in high school athletic departments.

Ouchi (1981) asserted that trust is a critical underpinning for well-functioning organizations.

Does this hold true for high school sport organizations? Not only are high school athletic

departments understudied organizations, but the role of trust within the department is also

underdeveloped

\section{Methodology}

In order to investigate the research questions and the model data were collected using the cluster sample method of six of the largest school in Albania.

Specifically, conducting the appropriate quantitative analyses required the collection of data

from at least 119 participants of the population chosen at random so all coaches would be included in the population. The goal was to obtain a random diverse sample using the cluster sampling method and random sampling to obtain at least 119 surveys for use in this study. A Power Analysis using G*Power 3.1. 3 was used to determine the minimum sample size needed for a multiple linear regression with three predictors in order to detect a moderate effect size of $0.15, a=0$. 05 level of significance, and a power of 0.95 , a minimum sample size of 119 is needed.

\section{Instrumentation and Variables}

In order to explore the research questions, operational measures of organizational trust

and mindfulness are necessary. The study used two instruments to collect data. The Athletic

Department Trust was used to measure coaching staff perception of organizational

Trust and the Higher Education Faculty.

The pilot study was conducted at two university athletic departments. In order to ensure

construct validity of the measures, an exploratory factor analysis, using Statistical Package for

the Social Sciences (SPSS), was performed afterwards. The study was conducted using a webbased survey system (Survey Monkey). A total of 100 coaches were solicited for participation in the study and fifty-one of those responded, for a response rate of $51 \%$, which according to Field (2005), a sample of 51 is sufficient for a pilot study (Tingle, 2011).

A principal component analysis with a varimax rotation was used to explore construct

validity of the athletic department mindfulness scale. Three unique factors were found after the

first analysis, but a careful examination of the factor structure indicated that many variables

loaded highly on more than two factors. The goal of the factor analysis was to reduce the size of

the instrument without disrupting the factor structure or the reliability of the survey instrument. 


\section{Data Collection}

The population of this study consisted of 54 high schools with athletic departments and over 1,000 coaches. A cluster sample of six of the largest school in Albania was taken and a simple random sample selection process was used to solicit the approximate 1,000 participants used to obtain the 134 surveys used in data analysis. At the high school level many athletic directors also coach a sport, therefore great care was taken to ensure that no athletic directors received an invitation to participate. In the case of the athletic director also being a In this study, the researcher received 134 survey responses. Of the 134 responses, only

109 were used in the quantitative analyses of the study. There were three survey responses that did not agree with consent to participate. There were twenty-two others that did consent but did not complete any part of the survey after the consent form; therefore, these responses were eliminated from the analysis. The elimination process used was listwise deletion default in SPSS and MPLUS 6 statistical packages. There were 109 responses used for the descriptive statistics of the athletic director mindfulness instrument and 98 responses used for the descriptive statistics of the organizational trust instrument. Finally, the correlations and regression analyses were computed using $(\mathrm{N}=98)$.

Data analysis was conducted through the use of descriptive statistics and multiple linear least-squares regression. The focus of the study was to gain knowledge and understanding of the coaches' level of trust in the athletic director, colleagues, and student-athlete. Also, the study was focused on how coaches perceive the mindfulness of the athletic director. The first step in the data analysis process was to find the descriptive statistics for each variable. The descriptive statistics were an examination of ranges, means, and standard deviations used to locate any unusual findings.

Descriptive statistics, including means and standard deviations were calculated for the three measures of organizational trust and for athletic director mindfulness.

The dependent variable was the total score of athletic director mindfulness on the Organizational Mindfulness instrument with the predictors being values of the three sub-scales on the Organizational Trust instrument. Assumptions were examined to insure that no multicollinear 
relationships exist between the three predictors.

Using the framework described by Hoy et al. (2006), the independent variable organizational trust consists of three specific measures: coach's trust in athletic-director, coach's

trust in colleagues, and coach's trust in student-athletes. The dependent variable in this study was coach's perception of athletic director mindfulness (see Figure 2). The decision to explore this relationship between organizational trust and mindfulness is based on previous research on trust and mindfulness (Hoy, 2003; Hoy \& Tschannen-Moran, 1999; Hoy et al., 2006; Langer, 1989; Langer \& Moldoveanu, 2000; Shoho \& Smith, 2004; Smith \& Shoho, 2007; Tschannen-Moran \& Hoy, 2000; Weick \& Sutcliffe, 2001, 2007) and the researcher's interest in expanding the research to include high school athletic departments

\section{Implications for Practice}

The findings in this study provide suggestions for both practitioners and researchers. In high school athletic departments, the three dimensions of organizational trust seem to influence one another as they combine and contribute to the environment that enhances athletic director mindfulness. The results of the study indicate that when coaches perceive their athletic director as being trustworthy, he or she is more likely to operate using the principles of mindfulness as the athletic director. This study does add to the growing body of research in the area of organizational trust and mindfulness due to the strong relationship that was revealed between the two constructs. It is hoped that the practical and research implications discussed next will aid both practitioners and researchers in the improvement of the organizational culture of high school athletic departments.

Some school stakeholders and central office administrators may find value in the results of this study. High school administrators who are aware of the connection may choose to hire an athletic director more likely to create an organizational climate in which trusting behaviors are recognized and then rewarded. Also, by using these two instruments high school administrators might uncover the coach's perception regarding trust and mindfulness of the athletic director. Through this view of the department the administrators can draw conclusions as to whether the athletic department is in need of attention, and then he or she could use the data to investigate the 
causes, and then take the appropriate steps to address those issues.

Furthermore, athletic directors interested in understanding current trust levels and the

impact of trust on decision-making could use this study to justify changing the climate of the

athletic department. Coaches might benefit from the research results with information to aid

them in the job search process. Those coaches who become aware of the relationships found

might be more selective in their job decisions, and might inquire about the current levels of trust

and mindfulness at potential future jobs. Finally, prospective student-athletes and their families

may find the resulting information useful when deciding what schools to attend and whether or

not to participate in athletics.

\section{Conclusion.}

Athletic Department in Albania is not an agreement with the clubs that train athletes or sports clubs for football are that the atletikor preparers often include as an assistant coach. Finally there is an initiative of the Ministry of Education and Sports to establish such cooperation and relations to make this part of plans and curricula, but it still has not been realized in practice, because Albania has an acute shortage of infrastructure.

However in terms of conception and formatting a clear relationship and with perspective to create and respect system necessary autonomy sports Albania remains private more to do. If at the central stepped forward in this regard are on track, at local sports movement-structure relationships public are still far from reality social and claims that the law poses.

Athletic directors and high school administrators are encouraged to make use of research

findings and the research instruments presented to further explore organizational trust and

mindfulness. Due to a lack of research on the relationship of trust and mindfulness in high

athletic departments, the two research instruments can be utilized to take a

closer look at this relationship and other organizational processes in high school athletic

departments. The intent of this study was to explore the relationship between organizational trust and perception of athletic director mindfulness operating in high school athletic departments. Athletic directors and coaches that place an importance on trust are: benevolent, competent, honest, open, and reliable. Furthermore, the findings in the study suggest that high school athletic departments with higher levels of trust are more likely to have athletic directors who are: preoccupied with failure, reluctant to oversimplify, sensitive to operations, committed to resilience, and defer to experts when needed. Hopefully the findings in this study support the current trust-building and mindful strategies in order to aid high school athletic department stakeholders in their visions and missions for bettering their overall school structure.

\section{Recommendations}

1. There is a need to do more research in the relationship of the two constructs of this study:

organizational trust and its relationship to athletic director mindfulness. The research

would be encouraged to view a close game as an opportunity to remodel strategies 
rather than just evidence that current approaches are most effective;

2. Establish awareness of vulnerabilities in the system. Coaches need to be aware of weaknesses surrounding the department so they are not shocked by unexpected events.

3. Demonstrate humbleness in order to keep coaches from being blindsided. Success

is important in the athletic realm, but one must not become too complacent;

4. Welcome the occasional bad day. These days should be used as learning opportunities and not viewed as problems. For example, losing a player to injury can provide the coaches with an opportunity to make roster changes and preparation changes;

5. Establish an environment that is free and open to mistakes. Basic organizational tasks can be improved by simplification (e. g., game schedules), other complex functions (e. g. off-season training program plans) require more creativity;

6. Develop skepticism in the department. Coaches and/or student-athletes need skepticism at times to aid in raising their awareness of opponents as well as raising their intensity to learning the system;

\section{Reference}

1. ChappeletJ. -L. (2008). "The International Olympic Committee and the Olympic

System. The governance of world sport", Routledge, London.

2. Hoy, W. K., \& Tschannen-Moran, M. (2003). The conceptualization and measurement of faculty trust in schools. In W. K. Hoy \& C. G. Miskel (Eds. ), Studies in leading and

organizing schools (pp. 181-207). Greenwich, CT: Information Age Publishing.

Hoy, W. K., \& Tarter, C. J. (2004). Organizational justice in schools: no justice without trust. International Journal of Educational Management, 18(4), 250-259.

Hoy, W. K., Gage, C. Q., \& Tarter, C. J. (2004). Theoretical and empirical foundations of mindful schools. In W. K. Hoy and C. G. Miskel (Eds. ), Educational administration, policy, and reform: Research and measurement (pp. 305-335). Greenwich, CT: Information Age Publishing. 
Hoy, W. K., Gage, C. Q., \& Tarter, C. J. (2006). School mindfulness and faculty trust: necessary conditions for each other? Educational Administration Quarterly, 42(2), 236.

Barrett, M. S. (2008). Transferring high reliability theory: Expanding the reach of mindful practices. Unpublished Dissertation, North Dakota State University of Agriculture and Applied Science.

Baum, J. A. C., \& Ingram, P. (1998). Survival-enhancing learning in the Manhattan hotel industry, 1898-1980. Management Science, 44(7), 996-1016.

Bennis, W., \& Nanus, B. (1985). Leaders: The strategies for taking charge. New York: Harper and Row.

Beyer, J. M. \& Hannah, D. R. (2000). The cultural significance of athletics in U. S. higher education. Journal of Sport Management, 14(2), 105-132.

Bigley, G. A., \& Pearce, J. (1998). Straining for shared meaning in organization science: Problems of trust and distrust. Academy of Management Review, 23(3), 405-422. Bishop, S. R., Lau, M., Shapiro, S., Carlson, L., Anderson, N. D., Carmody, J., Segal, Z. V., defintion. Clinical Psychology: Science and Practice, 11(3), 230-241.

Creed, W. E. D., \& Miles, R. E. (1996). Trust in organizations: A conceptual framework linking organizational forms, managerial philosophies, and the opportunity costs of control. In T. R. Tyler \& R. M. Kramer (Eds. ), Trust in organizations: Frontiers of theory and research (pp. 16-38). Thousand Oaks, CA: Sage Publications.

Cunningham, J. B., \& MacGregor, J. (2000). Trust and the design of work: Complementary constructs in satisfaction and performance. Human Relations, 53(12), 1575-1591.

Curzon-Hobson, A. (2002). A pedagogy of trust in higher learning. Teacher in Higher Education, 7, 265-277. 